\title{
Determination of Micromotion at the Implant Bone Interface - An In- Vitro Methodologic Study
}

\section{Matthias Karl ${ }^{1 *}$, Friedrich Graef $^{2}$ and Werner Winter ${ }^{3}$}

${ }^{1}$ Department of Prosthodontics, University of Erlangen-Nuremberg Dental School, 91054 Erlangen, Germany

${ }^{2}$ Department of Mathematics, University of Erlangen-Nuremberg, 91058 Erlangen, Germany

${ }^{3}$ Department of Mechanical Engineering, University of Erlangen-Nuremberg, 91058 Erlangen, Germany

\begin{abstract}
Dental implants lacking primary stability show increased levels of micromotion which may result in fibrous encapsulation instead of osseointegration. A novel experimental technique has been used for directly measuring implant displacement as a consequence of occlusal loading. Implants were inserted in bone surrogate material differing in density thereby measuring insertion torque and implant stability by means of resonance frequency analysis. Implants placed in bone with a density of $10 \mathrm{pcf}$ and loaded with a mean force of $62.7 \mathrm{~N}$ showed maximum mean displacement of 71.9 $\mu \mathrm{m}$. Significant differences in micromotion resulted from placing implants in bone with varying densities. Measurements of implant insertion torque correlated well with measurements of implant displacement. Implant stability measurements of specific implants showed consistency, no correlation between implant stability and maximum implant displacement could be established. It appears that a reliable assessment of bone quality may be best used for predicting micromotion at the implant-abutment interface.
\end{abstract}

Keywords: Dental implant; Bone density; Micromotion; Insertion torque; Primary stability

\section{Introduction}

Achieving sufficient primary stability is one of the most important goals during dental implant surgery [1]. The major parameters determining the amount of stability achieved include the quality of the alveolar bone [2-4], the surgical technique used as well as the design and surface topography of the implant placed [5]. In case of a lack of primary stability, any forces potentially acting on an implant may lead to a displacement of the implant relative to the bony socket what is described by the term micromotion [6,7]. It is generally accepted that micromovement occurring during the healing phase may lead to fibrous encapsulation of the implant once a threshold displacement of $50-150 \mu \mathrm{m}$ is surpassed [8-14]. In traditional treatment concepts, the risk of jeopardizing osseointegration has been minimized by applying late loading protocols for implant-supported reconstructions [15]. However, with the goal of shortening treatment times, novel concepts predominantly focus on early and immediate loading protocols [9]. As a consequence, micromotion at the bone-implant interface has gained increased recognition as a potential risk factor $[15,16]$.

Various techniques have so far been described in the literature for determining bone quality [17] and implant stability based on which the surgeon should decide whether or not immediate loading was feasible. Besides the subjective evaluation of conventional radiographs as well as recording the surgeon's tactile sensation during implant site preparation [18] 3D radiographs [19,20] providing numerical data as grey scales (CBCT - cone beam computed tomography) or Houndsfield units (CT - computed tomography), measurements of implant insertion torquel6and primary implant stability using resonance frequency analysis (Osstell, Osstell AB, Gothenburg, Sweden) or damping capacity assessments (Periotest, Gulden Medizintechnik, Modautal, Germany) have been reported [21-23]. Despite the huge body of literature available on these techniques [24] it is unclear whether clinical assessment techniques correlate with micromotion occurring at the implant bone interface $[25,26]$.

The aim of this in vitro study was to investigate whether measurements of implant displacement caused by oblique loading could be used for differentiating implants placed in bone surrogate material with varying densities. Furthermore, potential correlations between implant insertion torque, implant stability as measured by resonance frequency and implant displacement should be quantified.

\section{Material and Methods}

A total of 15 ( $n=5$ per group) bone level implants (Figure 1a) with diameters of $4.7 \mathrm{~mm}$ at the shoulder and $3.7 \mathrm{~mm}$ at the apex and a length of $16 \mathrm{~mm}$ (SCI-BioActive; AlfaGate; KfarQara, Israel) were placed in bone surrogate materials (Figure 1b) differing in density (Solid rigid polyurethane foam, 10 pound per cubic foot (pcf), $20 \mathrm{pcf}$,

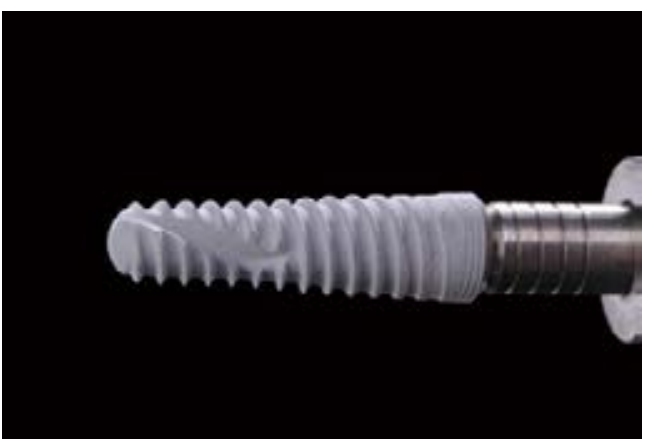

Figure 1a: Bone level dental implants used in this study which were inserted into bone surrogate materials leaving $3 \mathrm{~mm}$ of the implant extending from the surface of the bone blocks.

${ }^{*}$ Corresponding author: Dr. Matthias Karl, Zahnklinik 2 - Department of Prosthodontics, Glueckstrasse 11, 91054 Erlangen, Germany, Tel: +49 91318535802; Fax: +49 9131-8536781; E-mail: Matthias.Karl@uk-erlangen.de

Received February 23, 2015; Accepted March 07, 2015; Published March 11 2015

Citation: Karl M, Graef F, Winter W (2015) Determination of Micromotion at the Implant Bone Interface- An In-Vitro Methodologic Study. Dentistry 5: 289. doi:10.4172/2161-1122.1000289

Copyright: (c) $2015 \mathrm{Karl} \mathrm{M}$, et al. This is an open-access article distributed under the terms of the Creative Commons Attribution License, which permits unrestricted use, distribution, and reproduction in any medium, provided the original author and source are credited. 


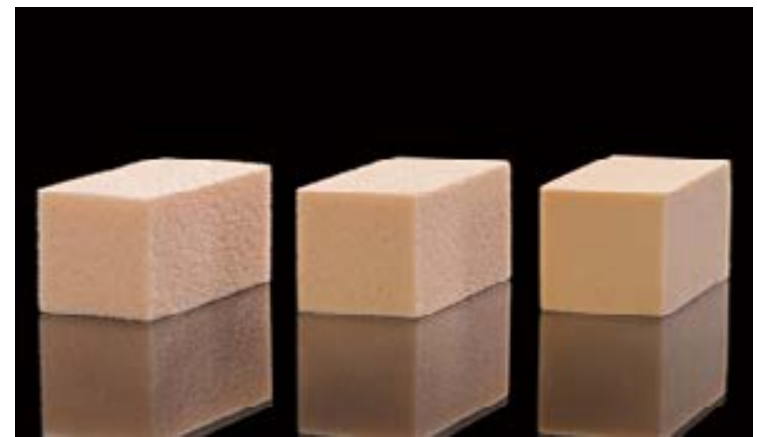

Figure 1b: Bone surrogate materials used in this study showing a homogeneous, solid structure and densities of 10 pcf, 20 pcf and 30 pcf (from left to right)

30 pcf; Sawbones Europe AB, Malmo, Sweden). Implant placement followed the clinical guidelines set by the implant manufacturer using parallel walled twist drills with diameters of 2.0, 2.8, 3.2, 3.65 and 4.2 $\mathrm{mm}$ which were used for creating implant recipient sites with a depth of $13 \mathrm{~mm}$. In order to have access to the implant body, the cervical portion $(3 \mathrm{~mm})$ of the implant was left extending from the surface of the bone surrogate material. Maximum insertion torque (Figure 2) was actively measured using a surgical motor (Elcomed, W\&H Dental work Bürmoos $\mathrm{GmbH}$, Bürmoos, Austria) and primary implant stability was determined by means of resonance frequency analysis (Osstell ISQ, Osstell AB, Gothenburg, Sweden).

For measuring implant displacement during oblique loading at a $30^{\circ}$ anglerelative to the long axis of the implants [27] the implantbone surrogate assemblies were positioned in a universal testing machine(inspect mini $3 \mathrm{kN}$, Hegewald und Peschke, Nossen, Germany). During loading of the implants with a force of $100 \mathrm{~N}$ at a crosshead speed of $100 \mathrm{~N} / \mathrm{s}$, implant displacement was quantified using a newly designed device (Figure 3 ) which transferred any occurring displacement onto bars equipped with extensometers (SandnerMesstechnik $\mathrm{GmbH}$,
Biebesheim, Germany). Maximum implant displacement was recorded using a measurement amplifier (Quantum X; Hottinger Baldwin Messtechnik GmbH, Darmstadt, Germany) and analysing software (catman, Hottinger Baldwin Messtechnik GmbH) (Figure 4). All implants were placed by an implantologist also conducting the torque and Osstell measurements while implant displacement was determined by a mechanical engineer.

Statistical analysis based on Wilcoxon rank tests was performed for comparisons between implants placed in different bone densities while Spearman's rank correlation coefficients were calculated for expressing potential correlations between insertion torque, ISQ and implant displacement. The level of significance was set at $\alpha=0.05$ for all statistical operations carried out (R, The R Foundation for Statistical Computing, Vienna, Austria; www.R-project.org).

\section{Results}

As expected, mean implant insertion torque increased from 3.9 $\mathrm{Ncm}$ in 10 pcf bone to $18.9 \mathrm{Ncm}$ in 30 pcf bone (Table 1). However, the difference in insertion torque between implants placed in $10 \mathrm{pcf}$ and 20 pcf bone was not significant $(p=0.0512$; Table 2a). Resulting implant stability prior to loading was greatest in $30 \mathrm{pcf}$ bone with a mean ISQ of 58.0, while the lowest mean ISQ of 49.8 was found in $20 \mathrm{pcf}$ bone. After loading, the ISQ values of implants placed in bone with densities of 20 and $30 \mathrm{pcf}$ remained more or less constant while a pronounced decrease in implant stability was seen in implants placed in $10 \mathrm{pcf}$ bone. As a consequence, lowest mean ISQ was measured in 10 pcf (35.4) while maximum mean ISQ was observed in $30 \mathrm{pcf}$ bone (60.6). Based on the statistical comparisons conducted, no significant difference in ISQ values between implants placed in different bone types could be observed, both before and after loading ( $p>0.05$; Table $2 b)$.

With the settings of the universal testing machine in terms of allowable displacement and time, it was not possible to exert a load of $100 \mathrm{~N}$ to all implants (Table 1). While mean loads beyond $90 \mathrm{~N}$ could be reached in implants placed in bone with densities of 20 and $30 \mathrm{pcf}$, the mean load applied on implants in 10 pcf bone was $62.7 \mathrm{~N}$. Despite

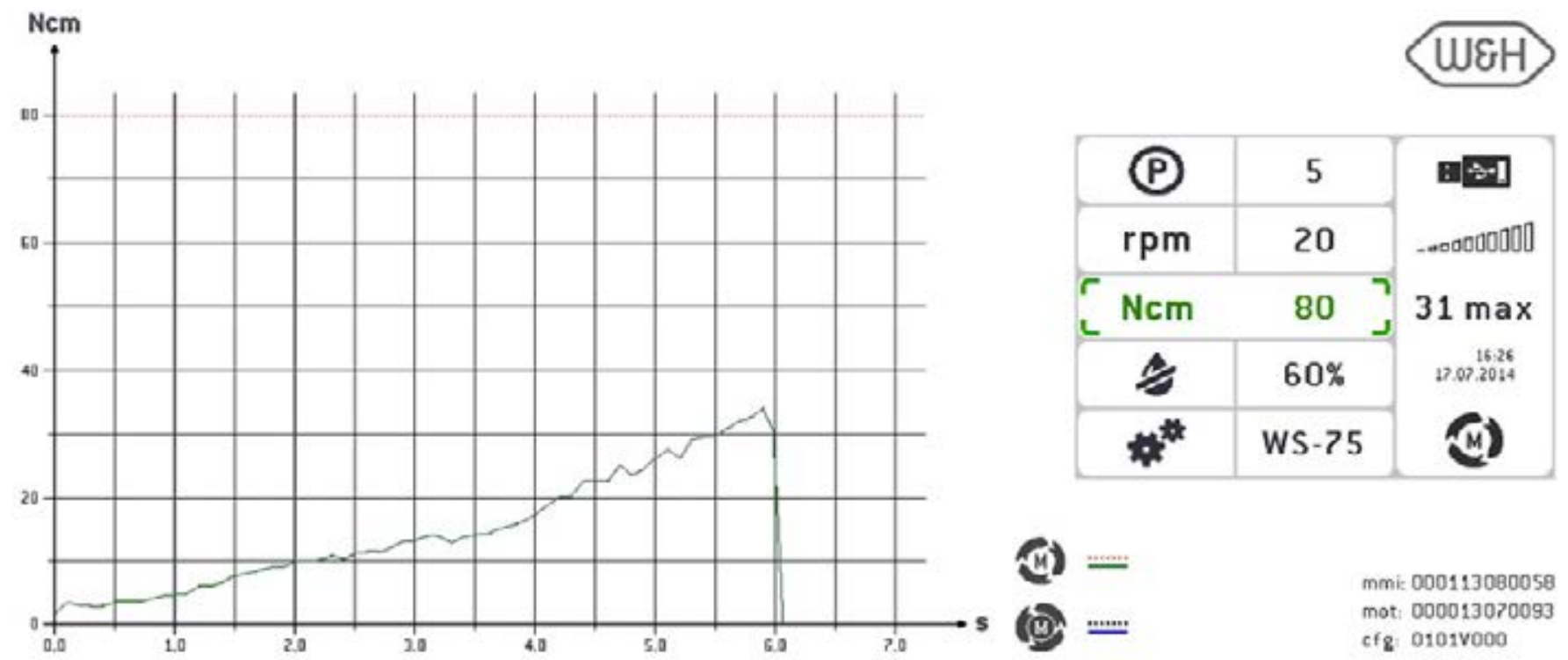

Figure 2: Screenshot from the surgical motor used for inserting the implants into the bone surrogate material. The maximum value reached is automatically given by the software. 


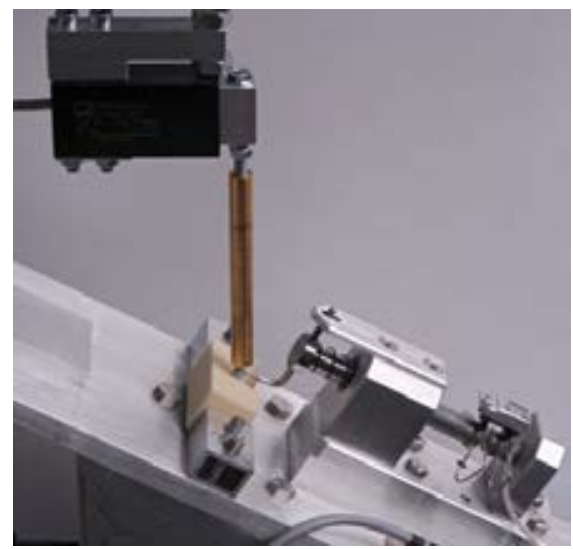

Figure 3: Specimen consisting of an implant placed in bone surrogate material placed in a universal testing machine at an angle of $30^{\circ}$ with respect to the long axis of the implant. Load is applied through the brass-colored bar while implant displacement is transferred to a remotely positioned extensometer.

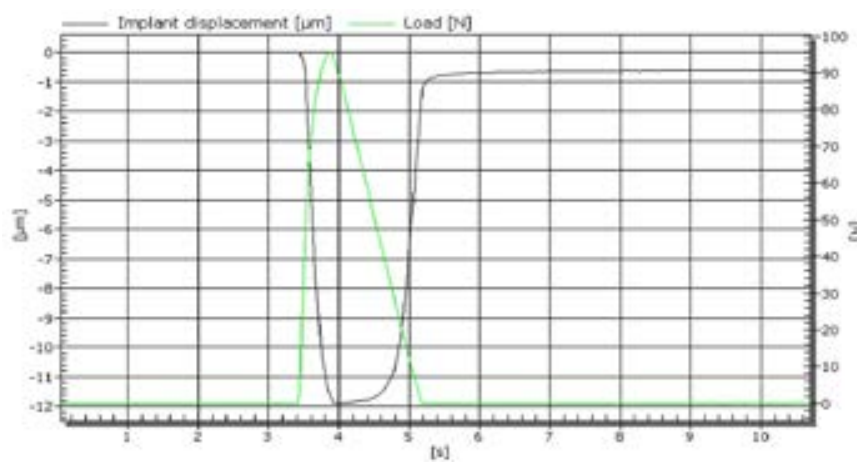

Figure 4: Screenshot from the analyzing software displaying load application and resulting implant displacement over time.

the lower load, maximum implant displacement during loading (71.9 $\mu \mathrm{m})$ was observed in these specimens, which was significantly higher as compared to implants placed in $30 \mathrm{pcf}$ bone $(\mathrm{p}=0.0159$; Table $2 \mathrm{c})$. With a p-value of 0.0571 , a slightly non-significant difference in implant displacement between 10 and 20 pcf specimens was observed. Maximum residual displacement $(21.7 \mu \mathrm{m})$ was measured in implants placed in $10 \mathrm{pcf}$ bone, which was significantly greater as compared to implants placed in $30 \mathrm{pcf}$ bone ( $\mathrm{p}=0.0369$; Table $2 \mathrm{c}$ ). Both, maximum and residual implant displacement decreased with increasing bone density (Table 1).

Implant insertion torque correlated significantly (Table 3 ) with maximum implant displacement $(\mathrm{p}=0.0171)$ and implant stability after loading ( $\mathrm{p}=0.0264)$, whereas implant stability before loading correlated with implant stability after loading $(\mathrm{p}=0.0131)$ and residual implant displacement $(\mathrm{p}=0.0129)$. Implant stability after loading showed significant correlations with maximum implant displacement $(\mathrm{p}=0.0008)$ and residual implant displacement $(\mathrm{p}=0.0001)$. Also, maximum and residual implant displacement correlated significantly with each other $(\mathrm{p}=0.0161)$.

\section{Discussion}

A novel measurement technique has been used for quantifying the displacement of dental implants inserted in bone surrogate materials differing in density [27]. It could be shown that changes in bone density significantly affect the amount of implant displacement occurring as a consequence of occlusal loading. Based on the statistical comparisons conducted and the correlation coefficients found, it appears that the method employed for quantifying implant micromotion shows greater sensitivity as compared to implant stability measurements using resonance frequency analysis. Measurements of implant insertion torque seem to be equally sensitive and correlate well with implant displacement values.

Resonance frequency analysis [23] showed consistent results within implants placed in one specific type of bone surrogate material, showing a slight trend towards lower stability after loading. Implant stability values recorded before and after loading correlated well with each other. However, prior to loading values not coinciding with bone density were observed thereby questioning the validity of such measurements $[22,24]$.

Considering the threshold values for non-detrimental micromotion reported by Szmukler-Moncler et al. $[14,15]$ those implants placed in bone with densities of 20 and 30 pcf would have had sufficient primary stability for achieving osseointegration. The implants placed in $10 \mathrm{pcf}$ bone showed micromotion in a critical range with load application leading to considerable residual implant displacement. The fact that levels of micromotion lying within the range of clinical relevance $[14,15]$ were measured with the current setup further validates the method applied, what was the major goal of this research. The displacement levels reported cannot be seen as absolute values for the implant type used as in most clinical situations, bone level implants do not extend from the alveolar crest.

Although the amount of micromotion occurring at the implant bone interface seems to be the decisive factor, the measurement technique applied for quantifying implant displacement cannot be applied in a clinical setting. Although not directly measuring implant micromotion, measurements of implant insertion torque [16,21-23] are clinically applicable and may provide some information on when immediate loading of implants is feasible. Based on the decreasing levels of implant displacement measured with increasing bone density, it might be possible to predict the amount of micromotion at the implant-bone interface based on a reliable assessment of bone quality $[1,3]$.

\section{Conclusion}

Given that this experiment was the first application of the novel measurement setup presented, no sample size calculation could be done beforehand. The sample size used certainly reflects an absolute minimum and partially was due to limited financial resources. The

\begin{tabular}{|c|c|c|c|c|c|}
\hline Bone density & $\begin{array}{c}\text { Insertion torque } \\
\text { [Ncm] }\end{array}$ & $\begin{array}{c}\text { Implant stability } \\
\text { before loading [ISQ] }\end{array}$ & $\begin{array}{c}\text { Implant stability after } \\
\text { loading [ISQ] }\end{array}$ & $\begin{array}{c}\text { Maximum } \\
\text { Load [N] }\end{array}$ & $\begin{array}{c}\text { Residual } \\
\text { displacement [ } \boldsymbol{\mu m} \text { ] }\end{array}$ \\
\hline $10 \mathrm{pcf}$ & $3.87(0.55)$ & $54.80(6.76)$ & $35.40(16.77)$ & $62.74(10.94)$ & $71.88(36.38)$ \\
\hline $20 \mathrm{pcf}$ & $8.30(4.40)$ & $49.80(10.64)$ & $49.40(11.01)$ & $90.77(7.31)$ & $21.69(16.67)$ \\
\hline $30 \mathrm{pcf}$ & $18.88(9.47)$ & $58.00(5.34)$ & $60.60(3.91)$ & $95.49(0.32)$ & $2.81(3.01)$ \\
\hline
\end{tabular}

Table 1: Mean values and standard deviations for all parameters investigated in this study. 


\begin{tabular}{|l|l|l|l|}
\hline & $10 \mathrm{pcf}$ & $20 \mathrm{pcf}$ & $30 \mathrm{pcf}$ \\
\hline $20 \mathrm{pcf}$ & & 0.0512 & $\mathbf{0 . 0 3 6 9}$ \\
\hline $30 \mathrm{pcf}$ & & & $\mathbf{0 . 0 3 6 7}$ \\
\hline
\end{tabular}

Table 2a: P-values for comparisons between implants placed in different bone types based on implant insertion torque; (Wilcoxon rank test; $\alpha=0.05$; significant values are written in bold).

\begin{tabular}{|l|l|l|l|}
\hline & $10 \mathrm{pcf}$ & $20 \mathrm{pcf}$ & $30 \mathrm{pcf}$ \\
\hline $10 \mathrm{pcf}$ & & 0.4005 & $\mathbf{0 . 5 9 9 3}$ \\
\hline $20 \mathrm{pcf}$ & 0.0937 & & $\mathbf{0 . 2 4 7 7}$ \\
\hline $30 \mathrm{pcf}$ & 0.0740 & 0.0947 & \\
\hline
\end{tabular}

p-values for comparisons between implants placed in different bone types based on implant stability after loading; (Wilcoxon rank test; $\alpha=0.05$; significant values are written in bold)

Table 2b: P-values for comparisons between implants placed in different bone types based on implant stability before loading; (Wilcoxon rank test; $\alpha=0.05$; significant values are written in bold).

\begin{tabular}{|l|l|l|l|}
\hline & $\mathbf{1 0}$ pcf & $\mathbf{2 0}$ pcf & 30 pcf \\
\hline 10 pcf & & 0.0571 & $\mathbf{0 . 0 1 5 9}$ \\
\hline 20 pcf & 0.1904 & & $\mathbf{0 . 0 1 5 9}$ \\
\hline 30 pcf & $\mathbf{0 . 0 3 6 9}$ & 0.4534 & \\
\hline
\end{tabular}

$p$-values for comparisonsbetween implants placed in different bone types based on residual displacement; (Wilcoxon rank test; $\alpha=0.05$; significant values are written in bold)

Table 2c: P-values for comparisons between implants placed in different bone types based on maximum displacement; (Wilcoxon rank test; $\alpha=0.05$; significant values are written in bold).

\begin{tabular}{|c|c|c|c|c|c|}
\hline & $\begin{array}{c}\text { Insertion } \\
\text { torque } \\
{[\mathrm{Ncm}]}\end{array}$ & $\begin{array}{c}\text { Implant } \\
\text { stability } \\
\text { before } \\
\text { loading } \\
\text { [ISQ] }\end{array}$ & $\begin{array}{c}\text { Implant } \\
\text { stability } \\
\text { after } \\
\text { loading } \\
\text { [ISQ] }\end{array}$ & $\begin{array}{c}\text { Maximum } \\
\text { displacement } \\
{[\mu \mathrm{m}]}\end{array}$ & $\begin{array}{c}\text { Residual } \\
\text { displacemen } \\
{[\mu \mathrm{m}]}\end{array}$ \\
\hline $\begin{array}{c}\text { Insertion torque } \\
{[\mathrm{Ncm}]}\end{array}$ & & 0.3059 & 0.0264 & 0.0171 & 0.2730 \\
\hline $\begin{array}{l}\text { Implant stability } \\
\text { before loading } \\
\text { [ISQ] }\end{array}$ & 0.3080 & & 0.0131 & 0.4970 & 0.0129 \\
\hline $\begin{array}{l}\text { Implant stability } \\
\text { after loading [ISQ] }\end{array}$ & 0.6116 & 0.6230 & & 0.0008 & 0.0001 \\
\hline $\begin{array}{c}\text { Maximum } \\
\text { displacement }[\mu \mathrm{m}]\end{array}$ & -0.6970 & -0.2072 & -0.8116 & & 0.0161 \\
\hline $\begin{array}{c}\text { Residual } \\
\text { displacement }[\mu \mathrm{m}]\end{array}$ & -0.4100 & -0.7179 & -0.9248 & 0.7016 & \\
\hline
\end{tabular}

Table 3: P-values for Spearman's rank correlation tests for all parameters measured ( $\alpha=0.05$; significant values are written in bold).

bone surrogate materials used are supposed to reflect the Lekholm and Zarb bone classes I (30 pcf), II and III (20 pcf) and IV (10 pcf) [17]. The homogeneous structure of the materials made from polyurethane foam [28] appears to be the major limitation of the study presented. In clinical reality, alveolar bone consists of a layer of cortical bone and underlying trabecular bone. It has been shown that the presence of a cortical layer greatly affects primary implant stability and hence seems to be more important compared to the underlying structure [29]. Furthermore, only one specific loading scenario mimicking the situation of anterior teeth was considered which resembles the ISO standard for fatigue testing of dental implants [30]. This seemed to be a viable approach as several millimeters of bone material surrounded the implants on all sides. In clinical situations, less bone volume is often seen in the buccal-lingual direction as compared to the mesial-distal direction.

\section{Acknowledgements}

This research received no specific grant from any funding agency in the public, commercial, or not-for-profit sectors.

\section{References}

1. Karl M, Palarie V, Nacu V, Krafft T (2013) Effect of intraoperative bone quality testing on bone healing and osseointegration of dental implants. Int $\mathrm{J}$ Oral Maxillofac Implants 28: 1254-1260.

2. Jaffin RA, Berman CL (1991) The excessive loss of Branemark fixtures in type IV bone: a 5-year analysis. J Periodontol 62: 2-4

3. Winter W, Krafft T, Steinmann P, Karl M (2011) Quality of alveolar boneStructure-dependent material properties and design of a novel measurement technique. J Mech Behav Biomed Mater 4: 541-548.

4. Malo MK, Rohrbach D, Isaksson H, Töyräs J, Jurvelin JS, et al. (2013) Longitudinal elastic properties and porosity of cortical bone tissue vary with age in human proximal femur. Bone 53: 451-458.

5. Romanos GE, Basha-Hijazi A, Gupta B, Ren YF, Malmstrom H (2014) Role of clinician's experience and implant design on implant stability. An ex vivo study in artificial soft bones. Clin Implant Dent Relat Res 16: 166-171.

6. Winter W, Klein D, Karl M (2013) Micromotion of dental implants - basic mechanical considerations. J Med Engin vol. 2013.

7. Winter W, Klein D, Karl M (2013) Effect of model parameters on finite element analysis of micromotions in implant dentistry. J Oral Implantol 39: 23-29.

8. Udofia I, Liu F, Jin Z, Roberts P, Grigoris P (2007) The initial stability and contact mechanics of a press-fit resurfacing arthroplasty of the hip. $J$ Bone Joint Surg Br 89: 549-556.

9. Romanos GE (2004) Present status of immediate loading of oral implants. J Oral Implantol 30: 189-197.

10. Holmes DC, Loftus JT (1997) Influence of bone quality on stress distribution for endosseous implants. J Oral Implantol 23: 104-111.

11. Holst S, Geiselhoeringer H, Wichmann M, Holst Al (2008) The effect of provisional restoration type on micromovement of implants. J Prosthet Dent 100: 173-182.

12. Kawahara H, Kawahara D, Hayakawa M, Tamai Y, Kuremoto T, et al. (2003) Osseointegration under immediate loading: biomechanical stress-strain and bone formation--resorption. Implant Dent 12: 61-68.

13. Brunski JB (1999) In vivo bone response to biomechanical loading at the bone/ dental-implant interface. Adv Dent Res 13: 99-119.

14. Szmukler-Moncler S, Salama H, Reingewirtz Y, Dubruille JH (1998) Timing of loading and effect of micromotion on bone-dental implant interface: review of experimental literature. J Biomed Mater Res 43: 192-203.

15. Szmukler-Moncler S, Piattelli A, Favero GA, Dubruille JH (2000) Considerations preliminary to the application of early and immediate loading protocols in dental implantology. Clin Oral Implants Res 11: 12-25.

16. Trisi P, Perfetti G, Baldoni E, Berardi D, Colagiovanni M, et al. (2009) Implant micromotion is related to peak insertion torque and bone density. Clin Ora Implants Res 20: 467-471.

17. Lekholm U, Zarb GA (1985) Patient selection and preparation, in Branemark P-I, Zarb GA, Albrektsson T (eds): Tissue Integrated Prostheses: Osseointegration in clinical Dentistry. Chicago, IL, Quintessence Publishing; 199-209.

18. Trisi P, Rao W (1999) Bone classification: clinical-histomorphometric comparison. Clin Oral Implants Res 10: 1-7.

19. Norton MR, Gamble C (2001) Bone classification: an objective scale of bone density using the computerized tomography scan. Clin Oral Implants Res 12 : $79-84$

20. Rebaudi A, Trisi P, Cella R, Cecchini G (2010) Preoperative evaluation of bone quality and bone density using a novel CT/microCT-based hard-normal-soft classification system. Int J Oral Maxillofac Implants 25: 75-85.

21. Lukas D, Schulte W, König M, Reim M (1992) High-speed filming of the Periotest measurement. J Clin Periodontol 19: 388-391.

22. Karl M, Graef F, Heckmann S, Krafft T (2008) Parameters of resonance frequency measurement values: a retrospective study of $385 \mathrm{ITI}$ dental implants. Clin Oral Implants Res 19: 214-218. 
Citation: Karl M, Graef F, Winter W (2015) Determination of Micromotion at the Implant Bone Interface- An In-Vitro Methodologic Study. Dentistry 5: 289. doi:10.4172/2161-1122.1000289

23. Sennerby L, Meredith N (2008) Implant stability measurements using resonance frequency analysis: biological and biomechanical aspects and clinical implications. Periodontol 2000 47: 51-66

24. Ribeiro-Rotta RF, Lindh C, Rohlin M (2007) Efficacy of clinical methods to assess jawbone tissue prior to and during endosseous dental implant placement: a systematic literature review. Int J Oral Maxillofac Implants 22 289-300.

25. Holst Al, Karl M, Karolczak M, Goellner M, Holst S (2010) Quantitative assessment of orthodontic mini-implant displacement: the effect of initial force application. Quintessence Int 41: 59-66.

26. Goellner M, Schmitt J, Karl M, Wichmann M, Holst S (2011) The effect of axial and oblique loading on the micromovement of dental implants. Int $\mathrm{J}$ Oral Maxillofac Implants 26: 257-264.
27. Karl M, Taylor TD (2014) Parameters determining micromotion at the implantabutment interface. Int J Oral Maxillofac Implants 29: 1338-1347.

28. Orlando B, Barone A, Giorno TM, Giacomelli L, Tonelli P, et al. (2010) Insertion torque in different bone models with different screw pitch: an in vitro study. In J Oral Maxillofac Implants 25: 883-887.

29. Rozé J, Babu S, Saffarzadeh A, Gayet-Delacroix M, Hoornaert A, et al. (2009) Correlating implant stability to bone structure. Clin Oral Implants Res 20: 1140 1145

30. Karl M, Kelly JR (2009) Influence of loading frequency on implant failure under cyclic fatigue conditions. Dent Mater 25: 1426-1432. 